\title{
PENGARUH KOMPENSASI, DAN MOTIVASI TERHADAP KINERJA DOSEN DAN KARYAWAN STIE-STMIK MURA LUBUKLINGGAU
}

\author{
Badaruddin Nurhab \\ Dosen Fakultas Ekonomi Dan Bisnis Islam IAIN Bengkulu \\ Email: B_nurhab@yahoo.co.id
}

\begin{abstract}
This study aimed to investigate the effect of compensation and motivation on the performance of faculty and staff STIE-STMIK MURA Lubuklinggau research uses quantitative methods melaului nalisisi analisisi descriptive view of the help lines sofwe SPSS 18, the respondents in this study amounted to 100 men, results showed that compensation has a relationship strong, positive and significant impact on the value of the variable Motivation 0:46 hubungaan Compensation has a strong, positive and significant impact on the performance of lecturers with a value of 0.25. sedangakan hubungaan Motivation has a strong, positive and significant impact on performance value of 0.56
\end{abstract}

Keywords: Kompensasi, Motivasi, Kinerja Dosen dan Karyawan

\section{PENDAHULUAN}

Keberhasilan suatu organisasi dipengaruhi oleh kinerja pegawai, untuk itu setiap organisasi akan berusaha untuk meningkatkan kinerja karyawan dalam mencapai tujuan organisasi yang telah ditetapkan. Kinerja karyawan mengacu pada prestasi seseorang yang diukur berdasarkan standar dan kriteria yang ditetapkan oleh organisasi.Kinerja tersebut tidak dapat berhasil atau tidak dapat tercapai dengan baik, bila setiap karyawan atau para pelaku dalam suatu organisasi atau intansi belum menyumbangkan tenaga dan kemampuan sesuai dengan kebutuhan.
Salah satu cara manajemen untuk meningkatkan prestasi kerja, memotivasidan meningkatkan kinerja karyawan adalah melalui kompensasi. Hal ini senada dengan pendapat Wilson Bangun kompensasi yang baik dapat meningkatkan hasil kerja berupa, kinerja, kepuasan kerja, absensi, perputaran kerja. ${ }^{1}$

Secara sederhana kompensasi merupakan sesuatuyang diterima karyawan untuk balas jasa kerja mereka. Nova retnowati \& muclichan erma widia mengungkapkan kompensasi yang tinggi

\footnotetext{
${ }^{1}$ Wilson Bangun ....,2012:254
} 
pada seorang karyawan mempunyai implikasi bahwa organisasi memperoleh keuntungan dan manfaat yang oftimal untuk meningkatkan produktivitas karyawan, semakin banyak karyawan diberikan kompensasi yang tinggi maka tingkat prestasi karyawan akan semakin tinggi.

Sehingga dapat dilihat kompensasi sangat berpengaruh seknifikan terhadap peningkatan kinerja karyawan, bila mana kompensasi diberikan dengan baik berdampak pada peningkatan kinerja karyawan yang baik pula, demikian sebaliknya bila kompensasi diberikan tidak maksimal berdampak pada kinerja yang tidak maksimal pula. Oleh karena hubungan antar kedua variabel tersebut maka diajukan. Kompensasi berpengaruh positif dan signifikan terhadap kinerjakaryawan.

Menurut Hasibuan mengatakan
bahwa salah satu tujuan pemberian
kompensasi adalah, sebagai ikatan kerja
sama, pengadaan efektif, motivasi, stabilitas
karyawan, disiplin serta pengaruh serikat
buruh dan pemerintah.. Jika balas jasa yang

diberikan cukup besar, manajer akan mudah memotivasi bawahannya. $^{2}$

Selain kompensasi berpengaruh terhdapa kinerja, kompemsasi diduga berpengaruh terhadap motivasi karyawan yang dapat mempengaruhi kinerja karyawan tersebut.Motivasi muncul dari dalam diri individu, karena memang individu itu mempunyai kesadaran untuk berbuat.Manusia sperti ini jarang cincong atau mengerutu.Baginya berbuat adalah suatu kewajiban, laksana makan sebagai kebutuhan. Paksaan, ancaman, atau imbalan yang bersifat eksternal lainnya memang penting akan tetapi tidaklah lebih penting ketimbang aspek-aspek nirmaterial.

Expectancy theory (teori harapan), yang dikemukakan oleh Victor Vroom mendasarkan pada tiga konsep penting, salah satunya adalah valence (nilai) adalah segala prilaku mempunya martabat atau nilai tertentu, (daya atau nilai yang memotivasi) sebgai individu tertentu. Dalam teori ini digambarkan seseorang berpeluang untuk posisi yang lebih tinggi dengan gaji yang lebih besar. $^{3}$

\footnotetext{
${ }^{2}$ Hasibuan, Malayu SP. Manajemen Sumber Daya Manusia, Edisi Revisi, Jakarta: Penerbit Bumi Aksara, 2002, hlm.121

${ }^{3}$ Hasibuan..., 2002, hlm. 166
} 
Dari penjelasan diatas semakin jelas bahwa kompensasi sangat mempengaruhi motivasi, dengan motivasi yang meningkat sudah barang tentu akan meningkatkn kinerja karyawan. Oleh sebab itu Kompensasi berpengaruh positif dan signifikan terhadap kinerjakaryawan dengan motivasi kerja sebagai variabel yang mempengaruhi.

STIE-STMIK MURA Lubuklinggau merupakan salah satu organisasi /Perguruan tinggi yang juga mempunyai tugas yang berat, yaitu menyelenggarakan proses pendidikan, tertib administrasi, organisasi dan tata laksana kerjan, serta lebih utama lagi melakukan proses kegiatan belajar mengajar.

\section{METODELOGI PENELITIAN}

\section{A. Waktu dan Tempat Penelitian}

Waktu penelitian ini di mulai dari proses perencanaan hingga proses pelaporan selesai, terhitung dari bulan Desember 2012 s.d. bulan Januari 2013. Penelitian ini dilakukan di STIE-STMIK MURA lubuklinggau dengan alamat jalan Yosudarso Lubukkupang kecamatan Lubuklinggau Selatan I kota Lubuklinggau.

\section{B. Populasi dan Sampel}

Populasi yang dimaksud dalam penelitian ini adalah seluruh karyawan dan dosen STIE-STMIK MURA Lubuklinggau sebanyak 115 orang. Dan sampel dalam penelitian ini berjumlah 100 orang.

\section{Desain Penelitian}

Desain penelitian yang akan digunakan adalah desain penelitian deskritif kuantitatif yaitu penelitian yang mengunakan keadaan sebenarnya dari fenomena objek yang akan diteliti berdasarkan analisis statistic. Penetilian ini untuk melihat pengaruh langsung dan tidak langsung antara variabel - variabel bebas yang terdiri dari : kompensasi (X1) dan motivasi (X2) dengan variabel terikat kinerja pegawai ( X3 ).

\section{Kerangka Berpikir}

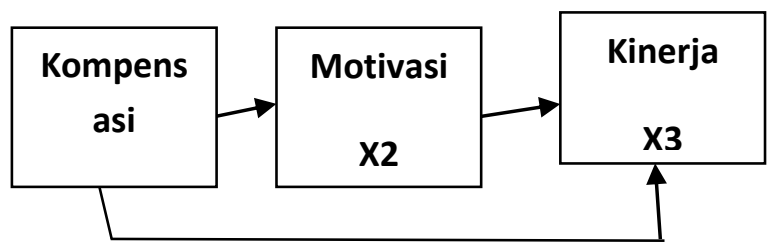

Gambar 2.1. Model Kerangka

\section{Pemikiran}

\section{E. Teknik Pengumpulan}

Penelitian ini menggunakan data yang diperoleh melalui responden melaui kusioner, dimana responden akan memberikan respon verbal dan atau respon tertulis sebagai tanggapan atas pernyataan yang berkaitan dengan kompensasi, motivasi, dan kinerja yang diberikan yang menjadi data primer untuk penelitian. 


\section{F. Metode Pengumpulan Data}

Data yang terkumpul akan diolah melaui SPSS (Statistical Package For Social Science). Dalam penelitian ini menggunakan Skala Linker dengan interval 1-5 yang dibuat dengan pilihan ganda.

\section{HASIL DAN PEMBAHASAN}

\section{A. Hasil}

a. Variabel Kompensasi

\section{Uji Instrumen Penelitian.}

Uji Validasi.

Validitas adalah tingkat keandalah dan kesahihan kuesioner yang digunakan. Intrumen dikatakan valid berarti menunjukkan kuesioner yang dipergunakan untuk mendapatkan data itu valid atau dapat digunakan untuk mengukur apa yang seharusnya di ukur.

\begin{tabular}{|c|c|c|c|}
\hline Indikator & $\begin{array}{c}\text { Corrected Item-Total } \\
\text { Correlation }\end{array}$ & $\mathbf{r}_{(0.05,98)}$ & Keterangan \\
\hline \multicolumn{4}{|c|}{ GAJI } \\
\hline G1 & 0.630 & 0.197 & valid \\
\hline $\mathrm{G} 2$ & 0.669 & 0.197 & valid \\
\hline G3 & 0.611 & 0.197 & valid \\
\hline G4 & 0.602 & 0.197 & valid \\
\hline G5 & 0.618 & 0.197 & valid \\
\hline \multicolumn{4}{|c|}{ INSENTIF } \\
\hline I1 & 0.632 & 0.197 & valid \\
\hline $\mathrm{I} 2$ & 0.600 & 0.197 & valid \\
\hline I3 & 0.572 & 0.197 & valid \\
\hline I4 & 0.626 & 0.197 & valid \\
\hline I5 & 0.576 & 0.197 & valid \\
\hline \multicolumn{4}{|c|}{ TUNJANGAN } \\
\hline $\mathrm{T} 1$ & 0.823 & 0.197 & valid \\
\hline $\mathrm{T} 2$ & 0.791 & 0.197 & valid \\
\hline $\mathrm{T} 3$ & 0.725 & 0.197 & valid \\
\hline $\mathrm{T} 4$ & 0.694 & 0.197 & valid \\
\hline T5 & 0.787 & 0.197 & valid \\
\hline \multicolumn{4}{|c|}{ BONUS } \\
\hline B1 & 0.787 & 0.197 & valid \\
\hline B2 & 0.757 & 0.197 & valid \\
\hline
\end{tabular}




\begin{tabular}{|c|c|c|c|}
\hline B3 & 0.769 & 0.197 & valid \\
\hline B4 & 0.721 & 0.197 & valid \\
\hline B5 & 0.750 & 0.197 & valid \\
\hline
\end{tabular}

b. Variabel Motivasi

\begin{tabular}{|c|c|c|c|}
\hline Indikator & $\begin{array}{c}\text { Corrected Item-Total } \\
\text { Correlation }\end{array}$ & $\mathbf{r}_{(0.05,98)}$ & Keterangan \\
\hline \multicolumn{4}{|c|}{ MOTIF } \\
\hline M1 & 0.634 & 0.197 & valid \\
\hline M 2 & 0.717 & 0.197 & valid \\
\hline M 3 & 0.756 & 0.197 & valid \\
\hline M 4 & 0.736 & 0.197 & valid \\
\hline M 5 & 0.744 & 0.197 & valid \\
\hline \multicolumn{4}{|c|}{ HARAPAN } \\
\hline H1 & 0.744 & 0.197 & valid \\
\hline $\mathrm{H} 2$ & 0.732 & 0.197 & valid \\
\hline H3 & 0.751 & 0.197 & valid \\
\hline $\mathrm{H} 4$ & 0.721 & 0.197 & valid \\
\hline H5 & 0.736 & 0.197 & valid \\
\hline \multicolumn{4}{|c|}{ NILAI } \\
\hline N1 & 0.716 & 0.197 & valid \\
\hline N2 & 0.628 & 0.197 & valid \\
\hline N3 & 0.666 & 0.197 & valid \\
\hline N4 & 0.681 & 0.197 & valid \\
\hline N5 & 0.684 & 0.197 & valid \\
\hline
\end{tabular}

Tabel 4. Interpretasi Korelasi menggunakan r

\begin{tabular}{|c|c|c|c|}
\hline Indikator & $\begin{array}{c}\text { Corrected Item-Total } \\
\text { Correlation }\end{array}$ & $\mathbf{r}_{(\mathbf{0 . 0 5}, 98)}$ & Keterangan \\
\hline \multicolumn{5}{|c|}{ KUALITAS PEKERJAAN } \\
\hline KLP1 & 0.492 & 0.197 & valid \\
\hline KLP2 & 0.632 & 0.197 & valid \\
\hline KLP3 & 0.400 & 0.197 & valid \\
\hline KLP4 & 0.594 & 0.197 & valid \\
\hline KLP5 & 0.528 & 0.197 & valid \\
\hline \multicolumn{2}{|c|}{ KUANTITAS PEKERJAAN } & 0.197 & valid \\
\hline KTP1 & 0.505 & 0.197 & valid \\
\hline KTP2 & 0.893 &
\end{tabular}




\begin{tabular}{|c|c|c|c|}
\hline KTP3 & 0.879 & 0.197 & valid \\
\hline KTP4 & 0.881 & 0.197 & valid \\
\hline KTP5 & 0.836 & 0.197 & valid \\
\hline \multicolumn{4}{|c|}{ KETEPATAN WAKTU } \\
\hline KW1 & 0.518 & 0.197 & valid \\
\hline KW2 & 0.570 & 0.197 & valid \\
\hline KW3 & 0.622 & 0.197 & valid \\
\hline KW4 & 0.600 & 0.197 & valid \\
\hline KW5 & 0.228 & 0.197 & valid \\
\hline \multicolumn{4}{|c|}{ KEHADIRAN } \\
\hline K1 & 0.638 & 0.197 & valid \\
\hline $\mathrm{K} 2$ & 0.788 & 0.197 & valid \\
\hline $\mathrm{K} 3$ & 0.893 & 0.197 & valid \\
\hline $\mathrm{K} 4$ & 0.526 & 0.197 & valid \\
\hline K5 & 0.864 & 0.197 & valid \\
\hline \multicolumn{4}{|c|}{ KERJA SAMA } \\
\hline KS1 & 0.685 & 0.197 & valid \\
\hline KS2 & 0.688 & 0.197 & valid \\
\hline KS3 & 0.623 & 0.197 & valid \\
\hline KS4 & 0.886 & 0.197 & valid \\
\hline KS5 & 0.659 & 0.197 & valid \\
\hline
\end{tabular}

Tabel 4. Interpretasi Korelasi menggunakan $r$

\section{Uji Reliabilitas.}

Uji reliabilitas berguna untuk menetapkan apakah instrumen yang dalam hal ini kuesioner dapat digunakan lebih dari satu kali, paling tidak oleh responden yang sama akan menghasilkan data yang konsisten. Dengan kata lain, reliabilitas/andal instrumen mencirikan tingkat konsistensi.

a. Variabel Kompensasi

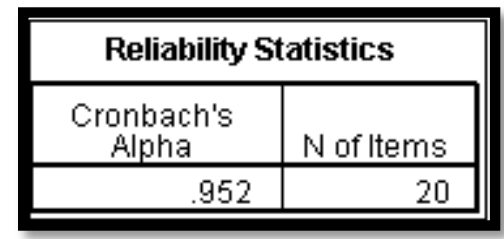

Tabel 4. Realibility Statistics

Dari tabel Realibility Statistics di atas, nampak koefisien Cronbach's Alpha sebesar 0.952. Suatu instrumen kuesioner Kompensasi dapat dikatakan reliable jika Koefisien Cronbach's Alpha diatas 0.6 sehingga dapat dikatakan instrumen kuesioner Kompensasi reliable karena $0.952>0.6$.

b. Variabel Motivasi

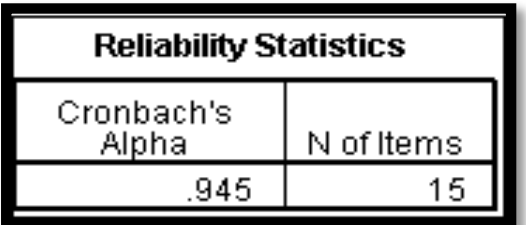




\section{Tabel 4. Realibility Statistics}

Dari tabel Realibility Statistics di atas, nampak koefisien Cronbach's Alpha sebesar 0.945. Suatu instrumen kuesioner Motivasi dapat dikatakan reliable jika Koefisien Cronbach's Alpha diatas 0.6 sehingga dapat dikatakan instrumen kuesioner Motivasi reliable karena $0.945>0.6$.

c. Variabel Kinerja

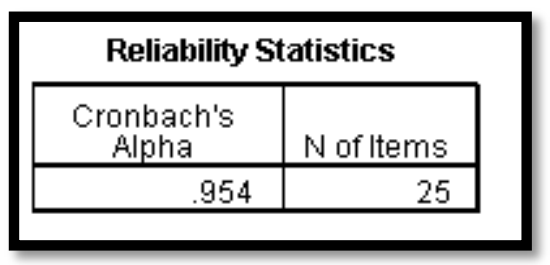

Tabel 4. Realibility Statistics

Dari tabel Realibility Statistics di atas, nampak koefisien Cronbach's Alpha sebesar 0.945. Suatu instrumen kuesioner Kinerja dapat dikatakan reliable jika Koefisien Cronbach's Alpha diatas 0.6 sehingga dapat dikatakan instrumen kuesioner Kinerja reliable karena $0.945>0.6$.

\section{Analisis Struktural Equation Modeling}

Hasil pengolahan data dengan Struktural Equation Modeling (SEM) secara model penuh (full model) dimana uji kesesuaian dan uji signifikansi kausalitas melalui uji koefisien regresi dilakukan. Penelitian ini menggunakan 3 variabel laten yaitu Motivasi, Kompensasi dan Kinerja. Variabel indikator motrivasi yang diukur yaitu Motif, Harapan, Nilai. Variabel indikator
Kompensasi yaitu Gaji, Insentif, Tunjangan, dan Bonus. Variabel indikator Kinerja yaitu Kualitas Pekerjaan, Kuantitas Pekerjaan, Ketepatan Waktu, Kehadiran, dan Kerja Sama. Hasil pengolahan data untuk analisis model penuh SEM ditampilkan pada gambar berikut ini.

Analisis Korelasi

Berikut merupakan korelasi antara variabel Motivasi , Kompensasi dan Kinerja.

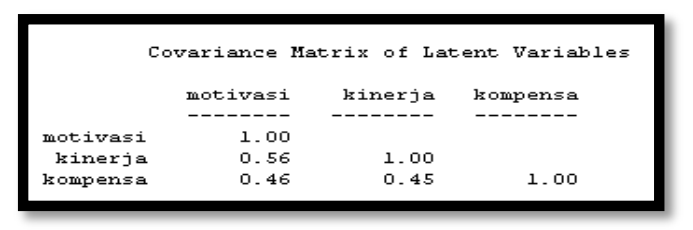

Tabel 4. Covariance Matrix

Berdasarkan Covariance Matrix diatas, dapat diketahui bahwa besarnya hubungan Kinerja terhadap Motivasi adalah 0.46, hubungan Kompensasi terhadap Kinerja adalah $\mathbf{0 . 4 5}$, serta hubungan Motivasi terhadap Kinerja adalah $\mathbf{0 . 5 6}$. Hal ini menunjukkan hubungan yang kuat, searah, dan signifikan atara Motivasi, Kompensasi dan Kinerja pada STIE-STMIK MURA.

Sumbangan kompensasi terhadap Motivasi adalah sebesar KP $K P=r^{2} x 100 \%=0.46^{2} \times 100 \%=21.16 \%$, artinya sumbangan $21.16 \%$ variabel Motivasi ini dijelaskan oleh variabel Kompensasi. Sumbangan Kompensasi terhadapa Kinerja adalah $K P=r^{2} \times 100 \%=0.45^{2} \times 100 \%=20.25 \%$, artinya Variabel Kinerja ini dijelaskan oleh Variabel Kompensasi sebesar 20.25\%. Sedangkan 
sumbangan Motivasi terhadap Kinerja adalah $K P=r^{2} x 100 \%=0.56^{2} \times 100 \%=31.36 \%$, artinya variabel Kinerja ini dijelaskan oleh variabel Motivasi sebesar 31.36\%.

\section{Analisis Jalur.}

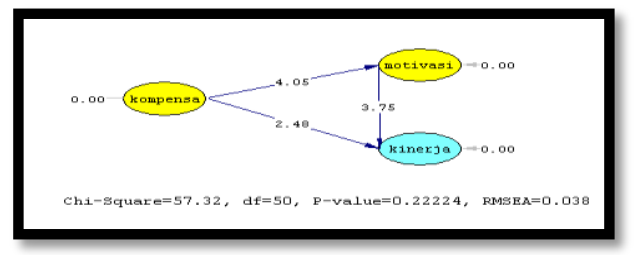

Gambar 4. Path Diagram dengan nilai loading faktor.

Pengujian Struktur Equation Model (SEM) dilakukan dengan dua macam pengujian yaitu uji kesesuaian model serta uji signifikansi kausalitas melalui uji koefisien regresi seperti yang diuraikan pada bagian berikut ini:

\section{B. PEMBAHASAN}

\section{Pengaruh Kompensasi Terhadap Motivasi.}

Hasil penelitian menunjukkan bahwa kompensasi memiliki hubungan yang kuat, positif dan signifikan terhadap variabel Motivasi pada dosen dan karyawan STIESTMIK MURA Lubuklinggau dengan nilai 0.46, sehingga semakin tinggi Kompensasi maka semakin tinggi juga Motivasi kerja dosen dan karyawan STIE-STMIK MURA Lubuklinggau.

Selanjutnya Vroom dalam mengatakan bahwa : "Kekuatan yang memotivasi seseorang untuk bekerja giat dalam mengerjakan pekerjaannya tergantung dari hubungan timbalbalik antara apa yang ia inginkan dan butuhkan dari hasil pekerjaan itu. ${ }^{4}$ Berapa besar ia yakin perusahaan akan memberikan pemuasan bagi keinginannya sebagai imbalan atas usaha yang dilakukannya itu".

Dalam teori pengharapan terdapat tiga hubungan, yaitu hubungan antara usaha dengan prestasi, hubungan prestasi dengan penghargaan perusahaan dan hubungan antara penghargaan perusahaan dengan tujuan karyawan. Apabila penghargaan yang diberikan oleh perusahaan sesuai dengan pengharapan dan dapat memuaskan kebutuhannya, maka karyawan tersebut akan termotivasi untuk lebih meningkatkan usaha/kinerjanya, sebaliknya apabila usaha yang dilakukan tidak mendapat penghargaan sesuai dengan harapan karyawan, maka karyawan yang bersangkutan akan merasa frustasi, sehingga tidak termotivasi untuk meningkatkan kinerjanya.

\section{Pengaruh Kompensasi Terhadap Kinerja.}

Hasil penelitian menunjukkan bahwa Kompensasi memiliki hubungaan yang kuat, positif dan signifikan terhadap Kinerja pada dosen dan karyawan STIE-STMIK MURA

\footnotetext{
${ }^{4}$ Hasibuan ..., 2001, hlm.116
} 
Lubuklinggau dengan nilai 0.25 , sehingga semakin tinggi Kompensasi maka semakin tinggi juga Kinerja kerja dosen dan karyawan STIE-STMIK MURA Lubuklinggau.

Menurut Robbins ${ }^{5} \quad$ kompensasi berdasarkan keterampilan adalah sesuai dengan teori ERG (Existence, Relatedness and Growth theory) dari Alderfer, sebab system pembayaran ini dapat mendorong karyawan untuk belajar, meningkatkan keterampilannya dan memelihara keterampilannya. Hal ini dapat diartikan, bahwa bagi karyawan yang ingin memenuhi kebutuhannya dengan lebih baik, maka pemberian kompensasi berdasarkan keterampilan akan menjadi pendorong baginya untuk lebih meningkatkan keterampilan, agar memperoleh kompensasi yang lebih tinggi, sehingga kebutuhannya dapat terpenuhi. ${ }^{6}$

\section{Pengaruh Motivasi Terhadap Kinerja.}

Hasil penelitian menunjukkan bahwa Motivasi memiliki hubungaan yang kuat, positif dan signifikan terhadap Kinerja pada dosen dan karyawan STIE-STMIK MURA Lubuklinggau dengan nilai 0.56. Sehingga

\footnotetext{
${ }^{5}$ Robbins, Stephen P,2006. Prilaku Organisasi. Indeks, Jakarta

${ }^{6}$ Muljani, Kompensasi Sebagai Motivator Untuk Meningkatkan Kinerja Karyawan, 2002, hlm.121
}

semakin tinggi Motivasi maka semakin tinggi juga Kinerja kerja dosen dan karyawan STIESTMIK MURA Lubuklinggau.

Berdasarkan hasil penelitian yang dilakukan Brownell dan McInnes (1986) diketahui bahwa motivasi mempunyai pengaruh positif terhadap kinerja. ${ }^{7}$

\section{Pengaruh Motivasi dan Kompensasi Terhadap Kinerja.}

Hasil penelitian menunjukkan bahwa variabel Motivasi dan variabel Kompensasi hubungaan yang kuat, positif dan signifikan terhadap variabel Kinerja pada dosen dan karyawan STIE-STMIK MURA Lubuklinggau dengan nilai 0.45 dan 0.25 , sehingga semakin tinggi Motivasi dan Kompensasi maka semakin tinggi juga Kinerja kerja dosen dan karyawan STIESTMIK MURA Lubuklinggau.

Hal ini sejalan dengan penelitian yang dilakukan oleh Haryono (2009), yang menyatakan bahwa kompensasi berpengaruh positif terhadap kinerja dengan motivasi kerja sebagai variable intervening. Hal ini menunjukkan bahwa adanya rasa puas dengan

\footnotetext{
${ }^{7}$ Suranta. Sri 2003. Pengaruh Gaya kepemimpinan Terhadap Kinerja Karyawan Perusahaan Bisnis Dengan Motivasi Karyawan Sebagai Variabel Pemoderasi. Perspektif: Jurnal Ekonomi Pembangunan, Manajemen dan Akuntansi, Vol. 8: 73-88.
} 
kompensasi yang diberikan baik yang berupa gaji, bonus tunjangan dan berbagai fasilitas yang memadai akan menumbuhkan motivasi yang tinggi dalam bekerja, karena para karyawan merasa dihargai dan didukung dalam bekerja. Adanya motivasi yang tinggi membuat karyawan menjadi lebih terfokus dan perhatian pada upaya mencapai hasil kerja yang baik dan sesuai harapan perusahaan sehingga hal ini menumbuhkan kinerja yang lebih baik dari para karyawan. ${ }^{8}$

\section{PENUTUP}

\section{Kesimpulan}

Kesimpulan dari penelitian mengenai pengaruh kompensasi dan motivasi motivasi terhdap kinerja Karyawan dan Dosen STIESTMIK MURA Lubuklinggau sebagai berikut :

1. Kompensasi berpengaruh positif dan Langsung terhadap kinerja, sehingga adanya peningkatan pemberian kompensasi akan meningkatkan kinerja karyawan.

2. Motivasi berpengaruh positif dan Langsung terhadap kinerja, sehingga adanya peningkatan pemberian kompensasi akan meningkatkan kinerja karyawan.

\footnotetext{
${ }^{8}$ Muljani...,2002, hlm.121
}

3. Kompensasi berpengaruh positif dan Langsung terhadap Motivasi, sehingga adanya peningkatan pemberian kompensasi akan meningkatkan kinerja karyawan.

4. Kompensasi berpengaruh tidak langsung terhadap kinerja melalui motivasi kerja, sehingga dapat disimpulkan bahwa motivasi kerja menjadi variable yang memediasi antara kompensasi terhadap kinerja karyawan.

Saran

Saran yang bisa disampaikan dari hasil penelitian yang didapat adalah sebagai berikut :

1. Pada faktor kompensasi masih perlu meningkatkan jumlah kompensasi yang diberikan kepada karyawan, khsusunya pemberian bonus yang lebih menarik yang disesuaikan dengan jam lembur karyawan, sehingga karyawan akan merasa lebih puas dalam bekerja dan dapat lebih termotivasi serta dapat meningkatkan kinerja karyawan.

2. Pada faktor motivasi kerja masih perlu adanya peningkatan hubungan yang baik antara karyawan, dengan saling menjalin komunikasi agar bekerja secara baik, sehingga hal ini akan membuat karyawan lebih termotivasi untuk bekerja lebih baik karena merasa mendapat dukungan dari 
sesame karyawan dalam menjalankan tugasnya.

\section{DAFTAR PUSTAKA}

Arikunto, Suharsini, 2002, Prosedur Penelitian: suatu pendekatan Praktik, Jakarta, PT Rineka Cipta

Anoki, H Dito, 2010, 'Pengaruh Kompensasi Terhadap Kinerja Karyawan PT, Slamet Langgeng Purbalingga Dengan Motivasi Kerja Sebagai Variabel Intervening, http://eprints.undip.ac.id.

Bangun, Wilson 2012. Manajemen Sumber Daya Manusia. Erlangga

Desseler, Gary, 2003. Manajemen Sumber daya Manusia. Edisi Indonesia. Jakarta: PT. Prenhallindo.

Fathoni, Abdurrahman, 2006. Manajemen Sumberdaya Manusia. Rineka Cipta

Handoko, T Hani.1995, Manajemen Personalia dan Sumber Daya Manusia, Edisi kedua, Yogyakarta, Penerbit BPPE, 2001.

Hasibuan, Malayu SP. 2002. Manajemen Sumber Daya Manusia, Edisi Revisi, Jakarta, Penerbit Bumi Aksara, 2002.
Muljani, Ninuk, Kompensasi Sebagai Motivator Untuk Meningkatkan Kinerja Karyawan, http://puslit.petra.ac.id/journals

Mangkunegara, A Anwar Prabu. 2001. Manajemen Sumber Daya Manusia, Bandung, Penerbit PT Remaja Kosda Karya Bandung.

Rivai, Veithzal, 2005, Manajemen Sumberdaya Manusia Untuk Perusahaan, PT. Rajagrafindo Persada, Jakarta

Robbins, Stephen P,2006. Prilaku Organisasi. Indeks, Jakarta

Suranta. Sri 2003. Pengaruh Gaya kepemimpinan Terhadap Kinerja Karyawan Perusahaan Bisnis Dengan Motivasi Karyawan Sebagai Variabel Pemoderasi. Perspektif: Jurnal Ekonomi Pembangunan, Manajemen dan Akuntansi, Vol. 8: 73-88.

Soekidjo Notoatmodjo.2009. Pengembangan Sumber daya Manusia. Rineka Cipta.

Sugiyono, 2004, Metodelogi Penelitian, Penerbit Remaja Rosdakarya, Bandung

Wibowo, 2007, Manajemen Kinerja, PT. Grahagrafindo, Jakarta 